\title{
DETECTION OF BID RIGGING IN PROCUREMENT AUCTIONS
}

\author{
Robert H. Porter
}

J. Douglas Zona

Working Paper No. 4013

\section{NATIONAL BUREAU OF ECONOMIC RESEARCH 1050 Massachusetts Avenue \\ Cambridge, MA 02138 \\ March 1992}

Porter gratefully acknowledges support from NSF Grant SES-8721231, nd the hospitality of the MIT Economics Department. An earlier version of this paper was presented at the April 1991 meeting of the NBER Industrial Organization Program, and in seminars at Chicago, Harvard, MIT, Stanford and Toulouse. We received helpful comments from the participants in these sessions, and from Steven Berry, Bo Honore, Whitney Newey, Bernard Reddy and John Sutton. Diane Karlsruher provided expert research assistance. This paper is part of NBER's research program in Industrial Organization. Any opinions expressed are those of the authors and not those of the National Bureau of Economic Research. 
NBER Working Paper \#4013

March 1992

\section{DETECTION OF BID RIGGING IN PROCUREMENT AUCTIONS}

\section{ABSTRACT}

This paper examines bidding in auctions for state highway construction contracts on Long Island in the early 1980 s, in order to determine whether bid rigging occurred. Detection of collusion is possible because of limited participation in the collusive scheme. The paper looks at differences in behavior between ring members and non-members. In these auctions, collusion did not take the form of a bid rotation scheme, in which only one ring member submits a bid. Instead, several ring members bid on most jobs. The apparent role of ring meetings prior to the auction was to designate a serious bidder, and its bid, and the other firms then frequently submitted phony higher bids. The bidding data indicate that the bids of non-cartel firms, as well as their rank distribution, were related to cost measures, such as how much backlog a firm was carrying. In contrast, the rank distribution of higher cartel bids was unrelated to similar cost measures, and differed from the distribution of the low cartel bid.

Robert H. Porter Department of Economics Northwestern University 2003 Sheridan Road Evanston, $\pi 60208$ and NBER
J. Douglas Zona

N.E.R.A.

One Main Street

Cambridge, MA 02142 
I. INTRODUCTION

Between 1982 and 1988, more than half of the criminal cases filed by the Antitrust Division of the Department of Justice involved bid rigging or price fixing in auction markets. ${ }^{1}$ Bid rigging appears to be a pervasive problem, with indictments in highway construction, the distribution of school milk, utility procurement and other auction markets. Typically, a government agency, and hence the taxpayer, was the victim.

This paper proposes econometric test procedures that are designed to detect the presence of bid rigging in procurement auctions. ${ }^{2}$ Our tests will be poor substitutes for a wiretap or a disclosure by a dissident ring member. However, our procedures may be preferable to the view that patterns of bid rotation, or relatively constant market shares, constitute irrefutable evidence of collusion. Rotating bids are consistent with competitive equilibria when there are decreasing returns to scale, such as when there are capacity constraints, as Zona (1986) demonstrates. Lang and Rosenthal (1991) show that the noncooperative mixed strategy equilibrium of a multiproject bidding game, in which firms simultaneously compete for

1 See U.S. General Accounting office (1990).

2 Accordingly, we refer to the intended victim as the buyer, and the bidding ring is a subset of the potential sellers. The effect of the ring, then, will be to inflate the price paid by the buyer. 
several contracts, may entail negative correlation between a firm's bids, or an apparent bid rotation pattern. Similarly, comparisons of winning bids and engineers' estimates of costs, that attempt to measure economic returns, may be unreliable. Engineer's estimates may be unduly influenced by historical bid patterns, and so be an inflated measure of true costs.

In general, finding a single test procedure to detect bid rigging is an impossible goal. As in most tests for the exercise of market power, the idea is to identify differences between the observable implications of collusive and competitive behavior. The difficulty is that both competitive and collusive equilibria depend, to a great extent, on the economic environment, such as the auction rules and the nature of the good being traded. As Hendricks and Porter (1989) argue, collusion in auctions can take many forms, and it is important to tailor empirical work to specific cases. For example, a cartel might adopt a pure bid rotation scheme, where members take turns submitting bids in individual auctions (according to a "phases of the moon" scheme, for example). Alternatively, cartel members in addition to the designated winner may submit higher complementary or frivolous bids, perhaps to create the appearance of competition. It is unlikely that any single test procedure could detect all collusive schemes, absent data on economic returns (in which case effective collusion might be detected by the presence of 
persistently high profits). As a consequence, structural modeliing and estimation are difficult, absent more detailed information. In environments where complementary bids are submitted, structural modelling may be impossible, because it is not clear what complementary bids might be intended to maximize, apart from being higher than the winner's bid.

If a broadly applicable test to detect collusion could be devised, a cartel with full participation should be able to choose complementary bids so that the overall bid pattern passed the test. Phantom bid schemes can be structured so that the difference between the low and second lowest bids looks competitive. Presumably, an auction procedure is employed precisely because the buyer is not aware of the exact costs of the individual sellers. Submitted bids could be designed to be consistent with competitive bidding based on some plausible realization of seller costs.

There is a small empirical literature on collusion in auctions. Feinstein, Block and Nold (1985) propose and test a model of a cartel that manipulates engineers' estimates of the costs of highway construction jobs, by submitting complementary bids relatively close to the winning bid. Zona (1986) propose a test for bid rigging in highway construction auctions based on a switching regression model. Comanor and Schankerman (1976) examine the propensity of bid rigging schemes to submit identical bids in 
individual auctions. McMillan (1991) describes Dango, the negotiation among bidders for Japanese public works contracts, that is very similar to the collusive mechanism allegedly employed by some of the firms in our sample. McClave, Rothrock and Ailstock (1978) analyze bidding patterns in Florida school bread markets. Finally, Howard and Kaserman (1989) propose a regression based method of calculating damages in bid rigging cases.

Our paper examines the bidding behavior of firms competing for state highway construction contracts on Long Island in the early 1980s. Our data are somewhat limited, as we shall explain, but detection of collusion is possible because of limited participation in the collusive scheme. Our methodology is intended to detect differences in behavior between ring members and nonmembers. Ring membership itself probably depends on unobservable factors which differ across firms, so that bidding differences may be structural rather than evidence of collusion. In our data, collusion apparently did not take the form of a bid rotation scheme. In that instance, collusion would be empirically indistinguishable from the hypothesis that bid participation decisions merely reflect unobservable characteristics of the firms, so that different firms specialize in different types of jobs. Instead, member firms submitted bids on most jobs. The role of ring meetings prior to the auction was to designate a serious bidder and its bid. The other 
members were then expected to submit higher complementary bids. Accordingly, our procedure distingulshes between the lowest cartel bid (recall, this is a procurement auction in which the lowest bid wins) and other cartel bids. We take as evidence of collusive behavior the fact that the lowest noncartel bidder's behavior is not statistically distinguishable from that of other noncartel firms, whereas the determinants of the low cartel bid differ from those of higher cartel bids. This discrepancy is characteristic of the levels of the submitted bids, as well as their rank distribution.

Section 2 of this paper describes the structure of New York state highway construction auctions. We document why these auctions may be susceptible to bidder collusion. In addition, a subset of the participating firms allegedly submitted noncompetitive bids on jobs not in our data set, and therefore constitute a candidate cartel in our data set. Section 3 outlines an econometric model of competitive bidding behavior. We then describe our test, which is designed to detect departures from competition that are consistent with the hypothesized nature of collusive bidding. The available data are described in more detail in Section 4, and our estimation and test results are presented in section 5 . 
II. THE MARKET

The New York State Department of Transportation (DOT) is required to solicit bids and award highway contracts to the lowest responsible bidder. ${ }^{3}$ To that end, the DOT perlodically distributes a "Notice of Highway Lettings" to a list of subscribers, to inform them of highway construction projects to be let in the near future. These notices include a very brief description of the project and a reference number to be used for further information. Firms that are interested in submitting a bid on these projects request plans and specifications from the Department. A "Plan Buyers List" is also available from the DOT, and it lists the firms that purchase plans for specific jobs. The list of plan buyers is also distributed to subscribers. On the day of the letting, sealed bids are opened and the identity of all bidders and their bids are announced to those present. The low bid is accepted provided that it is

3 In government auction markets, the lowest reasonable bid is accepted if the bidder is qualified. According to U.S. code, "Contracts for the construction of each project shall be awarded only on the basis of the lowest responsive bid submitted by a bidder meeting established criterla of responsibility." 23 U.S.C. $\$ 122(b)$ (1982). Under the same code, states are required to select contractors through a competitive bidding process when projects are completely or in part financed by federal funds. See Joyner (1985) for a more complete discussion of the bidding process and related law. 
"responsible." The DOT checks calculations, compares the bid to its own estimate of the job cost, and if it is satisfied, awards the contract. The DOT announces the results of the letting process, and all bids and contracts awarded, to subscribers via the DOT notice "Tabulation of Results."

Using the auction mechanism described above, the DOT awarded about $\$ 120$ million $^{4}$ in highway contracts from April 1979 through March 1985 in Nassau and Suffolk Counties on Long Island. According to our data, 186 contracts were let in this period, with 161 contracts awarded for less than $\$ 1$ million. A total of 66 firms bid on at least one of these 161 smaller DOT contracts. However, only 22 firms submitted bids on large jobs (over $\$ 1$ million), and 45 percent of the bids on large jobs were submitted by four firms.

According to local newspapers, one of the large firms was convicted in federal court of rigging bids on a Long Island highway construction project. While the rigged project predates our sample, it may not have represented an isolated event but rather a pervasive problem that may be evident in our data. We argue below that there are several reasons to expect collusion in this market. We describe a particular set of firms that may be able to profitably collude, and we specify a mechanism of bid rigging that is

4 All dollar amounts in this paper are expressed in constant 1969 dollars. 
consistent with casual observation of the behavior of these firms.

We think of collusion as an arrangement among a group of bidders, either explicit or implicit, that is designed to limit competition among the participants. Iimiting competition may enable the ring to increase profits. Several features of the Nassau-Suffolk DOT market may encourage firms to collude. Each significant feature of the market is described below.

Firms compete only on price. Under the terms of the contract, the winning bidder supplies labor and materials and produces output with specified characteristics. The definition of "output" is held constant over all bidders, implying a de facto homogeneous product. Product differentiation is not allowed. A cartel need only coordinate action in the price dimension to collude.

The DOT policy of publicly announcing the bids and the identity of bidders allows cartel members to detect deviations from cartel agreements. Undercutting or cheating would not go unnoticed. In addition, the availability of plan buyer lists allows ex ante common knowledge of the set of potential bidders. Prospective bidders know who they will be bidding against before they submit a bid. All of this information was readily available to firms in our data set, since the trade associations were subscribers to the DOT notices. For example, the information was routinely distributed by the contractors' association 
to member firms. A cartel should face less uncertainty, and therefore perhaps be more stable, in such an environment.

During the sample period, the DOT exhibited almost perfectly inelastic demand. Although the state sets an overall budget for the DOT based on requests from the Department, demand is largely exogenous. With one notable exception, ${ }^{5}$ every contract was ultimately awarded to the low bidder, regardless of the DOT estimate of the cost. As a result, any inflation of winning bids due to collusion would be completely captured as profits. Of course, successful collusion may result in fewer lettings in the future.

5 According to our data, in February 1983, the DOT solicited bids on a contract for resurfacing 0.8 miles of road. Eight bids were submitted and the lowest bid was about $\$ 4,000,000$. The DOT decided not to award the contract, because the low bid was unusually high relative to their own estimate of the cost. The contract was again put out to bid in May 1983. This time four bids were submitted, three by firms that had submitted a bid previously, and a fourth by a new firm. The low bid was 20 percent higher, and submitted by the previous low bidder. Again, the contract was not awarded. The contract was put out to bid again in February 1984, and this time three bids were submitted. All three firms had bid in both previous sales. The low bid was about 10 percent higher than the previous low bid, and about 30 percent higher than the low bid in the first letting. It is notable that the ranking of the bidders did not change, and the low bidder was the same firm in each of the auctions. Because of the unusual bidding patterns, the contract was not awarded through 1987. 
The set of firms submitting bids on large projects was small and fairly stable over the period analyzed, even though the DOT actively recruited New York City firms for work in Nassau and Suffolk Counties. Entry would have been difficult due to large transportation costs (the batch concrete and asphalt plants employed on large jobs are typically owned by the bidder), and control of local facilities by the incumbent firms. In addition, union locals could have exerted significant control over production. ${ }^{6}$ There may have been significant barriers to entry, and there was little entry in a growing market.

As described above, the market for large jobs was highly concentrated. Only 22 firms submitted bids on jobs over $\$ 1$ million. On the 25 largest jobs, 45 percent of the 76 bids were submitted by the four largest firms. Most of the remainder were from smaller firms that bid infrequently. In our sample of paving jobs, 575 bids were submitted on 116 lettings. sixteen firms bid on jobs of $\$ 1$ million or more. of

6 According to an article published in Newsday, insiders say leaders of the two most powerful construction unions on Long Island discouraged outside bidders by threatening future labor trouble. At least one of the unions covered the entire metropolitan area. Thus, when word spread that particular firms had "the inside track on large public bids on the Island and the unions wanted it that way...very few people missed the message."

(See Newsday, Sunday, November 18,1984, pp. 3, 30.) 
the 79 bids on the 25 largest paving jobs, ranging from approximately $\$ 940$ thousand to $\$ 8$ million, 46 percent were submitted by the four largest firms. In bidding for the larger contracts, a ring would not have faced much outside competition.

Firms had many opportunities to communicate with each other. Most bidders were active in the local trade associations. Joint bidding was also allowed, provided that multiple bids were not submitted. Some firms did, in fact, submit joint bids.

Lettings for larger jobs occurred fairly regularly, early each year. The regularity of the lettings may have tended to increase (and make more predictable) the discounted value of continued collusion compared to deviation from, and subsequent expulsion from, any agreement. Although several jobs were often let on a single day, typically only one large job was offered on any given day. Spacing the letting of large jobs may limit the profits that a defector could earn before other cartel members retaliated. Therefore, the timing of lettings may facilitate collusion.

Finally, firms were relatively homogeneous. All cartel firms bought variable inputs in the same market and presumably paid the same factor prices. ${ }^{7}$ The

7 We do not know if unions enforced common wage scales, but employees of all the firms were affiliated with the same labor unions. 
production process was the same for all firms (and usually specified by the terms of the DOT contract), with little technological change. In addition, the likely ring members were all headquartered on Long Island. However, heterogeneities may have existed because firms owned different mixes of capital equipment. Also, the production process could have exhibited a deep " $U$ "-shaped short-run average cost curve. Therefore, small changes in output may have induced large changes in average cost. Short-run heterogeneities can arise when job backlog affects average costs for firms that have previously been awarded contracts. In any event, these are short-run phenomena and all firms are similar in the long run. The long-run viability of a cartel is enhanced by this similarity.

To summarize, the characteristics of this particular market tend to facilitate collusion. There is a demonstrated ability of a group of competitors to coordinate actions (by joint bidding); there are relatively few bidders on large jobs; characteristics of the letting process could help cartel members police collusive arrangements; the DOT short-run demand elasticity is near zero; the geographic market is isolated; and barriers to entry seem to exist.

In 1984, one of the five biggest firms in Nassau and Suffolk Counties was convicted in federal court of rigging bids on a Long Island highway construction project. Four other firms were listed as unindicted 
co-conspirators. All five firms have been named as participants in bid-rigging schemes in separate antitrust or racketeering suits filed by New York State or Suffolk County. In each suit, a single job was analyzed. No systematic review of other contract lettings was conducted. This group of five firms may have been rigging bids on other jobs that were not analyzed (or have not yet resulted in indictments). For the purpose of this paper, the five firms constitute a candidate cartel, potentially operating in any DOT contract letting. We henceforward refer to them as "cartel" firms, where the quotations indicate the tentative nature of the classification. other bidders are henceforward dubbed "competitive." In the following sections, the cartel firms are individually referred to as Firms $2,3,4,10$ and $14 .^{8}$ If, in fact, cartel bids are competitive, then no systematic differences between the two groups of firms should be detected.

Notwithstanding the allegations of conspiracy by the cartel firms, inspection of the data also indicates that these firms represent a plausible cartel. The cartel firms submitted 54 percent of the bids on larger jobs, and were awarded 37 percent of all contracts. It is at least conceivable that the

8 Firm 10 stopped participating in DOT auctions very early in our sample of paving jobs, and instead specialized in other lines of business. 
group could profit by coordinating their bids. In addition, they did not behave like ruthless competitors. The five cartel firms submitted several joint bids over the period analyzed, demonstrating an ability and willingness to cooperate. Table 1 summarizes joint bidding by cartel firms during the sample period.

Table 1. Joint Bids by Cartel Firms

\begin{tabular}{||c|c|c|}
\hline & & Value of \\
Firms & Date & Winning Bid \\
\hline 4,2 & February 1980 & $\$ 5,300,000$ \\
3,14 & June 1980 & $\$ 7,300,000$ \\
3,14 & January 1982 & $\$ 4,000,000$ \\
$3,4,8$ & November 1984 & $\$ 8,000,000$ \\
\hline
\end{tabular}

Joint bids can be mechanisms for allocating the market and therefore indicative of bid-rigging. Joint bidding is illegal unless the specified work could not be performed without the combined capabilities of the participating firms, or if the bidders could not be competitive individually. 9 Whether or not the bids in Table 1 were legitimate, the cartel firms have a demonstrated ability and willingness to coordinate action.

Fundamentally, any bid-rigging scheme limits the number of competitive bids that are entered on a

9 See, for example, COMPACT $v$. Metropolitan Government of Nashville and Davidson City, 592 F. Supp. 1567 [1984]. 
particular job. Cartel members could limit competition on a job elther by refraining from bidding, or by submitting noncompetitive bids. If noncompetitive bids are submitted, then a phantom bidding scheme is being pursued. Many bid-rigging practices condemned by the courts have included phantom bidding. ${ }^{10}$ Under these schemes, a letting may appear to be competitive to both the buyer and noncartel firms.

The possibility of a cartel phantom bidding scheme is consistent with our data. The cartel firms regularly bid "against" each other. Table 2 shows the number of occasions on which one of the firms in the group bid against another in lettings of contracts involving paving. Joint bids were excluded from our data set.

Table 2 .

Simultaneous Bids by Cartel Firms on Paving Jobs

\begin{tabular}{||l|c|c|c|c|c|}
\hline & Firm 2 & Firm 3 & FIrm 4 & Firm 10 & Firm 14 \\
\hline Firm 2 & 48 & 37 & 34 & 1 & 11 \\
\hline Firm 3 & 37 & 86 & 56 & 1 & 15 \\
\hline Firm 4 & 34 & 56 & 71 & 2 & 14 \\
\hline Firm 10 & 1 & 1 & 2 & 3 & 1 \\
\hline Firm 14 & 11 & 15 & 14 & 1 & 20 \\
\hline
\end{tabular}

10 See, for example, United States $v$. Portsmouth Paving Corp., 694 F. 2nd 312, 325 [4th Cir. 1982] and United States v. Ashland-Warren, Inc., 507 F. Supp. 433, 438 [M.D. Tenn. 1982]. 
For example, Table 2 indicates that on the 48 occasions when Firm 2 submitted a bid, 37 bids were also submitted by Firm 3. At least one firm in the candidate cartel submitted an individual bid on all but two of the large jobs in our data. Table 3 shows the probability of multiple cartel bids on paving and nonpaving jobs, given that at least one cartel firm bids on a job. For example, at least one other cartel firm bid on a paving job 88 percent of the times when Firm 2 bid. Every time Firm 14 bid on a paving job, another cartel firm did as well. The probability that cartel firms bid against each other on nonpaving jobs is slightly lower, as demonstrated by the lower percentages reported in the second column of Table 3.

Table 3. Probability of Multiple Cartel Bids Given a Bid By a Cartel Firm

\begin{tabular}{||c|c|c||}
\hline Firm & Paving & $\begin{array}{c}\text { Non- } \\
\text { Paving }\end{array}$ \\
\hline Firm 2 & 888 & 758 \\
\hline Firm 3 & 798 & 558 \\
\hline Firm 4 & 898 & 808 \\
\hline Firm 10 & 678 & NA \\
\hline Firm 14 & 1008 & NA \\
\hline
\end{tabular}

In addition to the evidence from the bidding data, information obtained from insiders suggests that a phantom bidding scheme was employed by these firms. These sources describe the process. 
"We all sat at the conference table... one of the contractors would have a list of upcoming contracts ... they'd talk about the contract ... how much money ... who won the last one ... who should get this one ... The contractors who were tagged to be the low bidders would work out their bid figures ... The rest of the contractors would then come up with higher bids. " 11

Apparently, the five cartel firms named in the indictment, together with representatives of two unions, participated in these meetings. The alleged role of the union people was to communicate to the ring members after the meeting what the low bids would be, and perhaps to help enforce adherence to the scheme. For their participation, the union representatives allegedly received a kickback of one percent of the low bid if the job was won. ${ }^{12}$

To summarize, the available evidence suggests that a phantom or complementary bidding scheme may have been employed. We assume that the cartel bids may exhibit the characteristics of a phantom bidding scheme, rather than some other form of bid-rigging. We therefore concentrate on detecting this form of collusion.

Before proceeding, we should also report on two conventional indicators of the presence of a collusive

11 Newsday, Sunday, November 18, 1984, p. 3.

12 Again, see the article in Newsday for more detail. 
scheme. The first is the stability of market shares, the idea being that a cartel will seek to maintain stabllity in an effort to keep participants happy. In our sample of paving jobs, however, the annual market shares of cartel firms exhibited substantial variability. For example, Firm 10 stopped bidding on paving jobs early in our sample. (As indicated in Table 2, Firm 10 submitted only three bids in our sample.) The other firms also experienced variable market shares for paving jobs, as measured either by number of jobs won or the dollar value of the contracts. However, as documented in the Newsday article, market shares were quite stable for business on state highway and sewer contracts, including many jobs not in our sample, for more than a decade. Therefore, market shares on paving jobs might create an unwarranted impression of competitive bidding behavior. Within paving jobs alone, or within general highway lettings, there is no obvious pattern of rotation of winning bids to ensure market share stability.

Second, consider the distribution of cartel and competitive bids. In our sample of 116 paving jobs, there were 347 competitive bids on 103 jobs, and 228 cartel bids on 109 jobs. (All jobs received at least one bid.) The bid data are striking in that the distribution of cartel bids on individual contracts is more tightly concentrated than is the corresponding distribution for competitive bids. For example, on 
the 76 jobs recelving two or more cartel bids, the second lowest cartel bid is 4.96 per cent higher than the low cartel bid. (This statistic is based on the average difference between the logarithm of the two lowest bids.) On the 75 jobs recelving two or more competitive bids, the corresponding ratio is 6.25 per cent. Note that there are more competitive bids per job, and the two order statistics are closer on jobs with a higher number of bids, so that the reported discrepancy understates the differences between the distributions. This finding is similar to the results of Feinstein, Block, and Nold (1985) for North Carolina highway contracts, where noncompetitive bidding apparently led to clustering of bids, in an attempt to influence engineer's estimates of the cost of future lettings. This pattern is also consistent with an attempt to create the appearance of competition.

III. THE MODEL

A competitive bidder must determine an optimal bid given his likely costs and the probable distribution of the other firms' bids. For expositional purposes, we model this process as an independent values auction in which bidders know their 
own costs. ${ }^{13}$ We assume the following: the set of bidders on any particular job is common knowledge; costs for firm $i$ on job $t$ are random with a known distribution; costs are independently distributed across firms; firm i knows its own costs but only the distribution of the costs of its competitors; and firms are risk neutral. Note that we do not assume that the cost distributions are necessarily identical across firms or across jobs.

Based on these assumptions, the profit maximization problem for each firm is

$$
\max { }_{b} E \Pi(b)=\left(b-c_{i t}\right) \varphi_{1 t}(b)
$$

where $b$ is the submitted bid, $c_{1 t}$ is the cost for firm $i$ of job $t$, and $\varphi_{i t}$ is the probability that a bid of $b$ is the winning bid. The first term is the profits earned with bid $b$, while the second is the probability that the profits are realized. The probability of winning depends on the distribution of costs of other firms and on the bidding strategies adopted by the other bidders. (A strategy specifies a bid as a

13 To the extent that idiosyncratic seller cost differences are qualitatively more important than any uncertainties concerning aspects of the job that affect all sellers' costs symmetrically, the letting process is best modelled as an independent private values auction. 
function of own cost.) In equilibrium, the bid from firm $i$ on job $t$ will satisfy the first order condition

$$
\varphi_{1 t}\left(b_{1 t}\right)+\left(b_{1 t}-c_{1 t}\right) \frac{\partial \varphi_{1 t}\left(b_{1 t}\right)}{\partial b}=0
$$

The first order condition imposes structure on the equilibrium relationship between a firm's probability of winning and the level of its bid. Below, we analyze the determinants of a firm's probability of winning and those of its bid.

Analysis Based on the Level of Bids

Equation (1) can be taken as a characterization of equilibrium bidding strategies. We assume that equilibrium behavior satisfies the log-linear bidding rule

$$
\log \left(b_{i t}\right)=\alpha_{t}+\beta X_{1 t}+\epsilon_{i t}
$$

where $\alpha_{t}$ is an auction-specific effect, $X_{1 t}$ is a vector of observable variables affecting firm i's probability of winning or its observable costs on job $t$, and $\epsilon_{i t}$ represents private information, such as idiosyncratic cost effects, for firm $i$ on job $t$. The error term has expectation zero and auction-specific variance, denoted $\sigma_{t}{ }^{2}$. The variance of the error term can be a function of many variables, including the dispersion of private information on that job.

Equation (2) is potentially restrictive. It imposes a form of symnetry, in that firms are assumed 
to respond similarly to changes in the observable factors $x_{t t}$. In addition, all commonly observed auction specific information, such as job characterlstics and other aspects of the joint distribution of costs, are assumed to be captured in a common auction specific constant. We have adopted this formulation, in which between-firm rather than between-job differences are emphasized, because this dimension of our data is more informative. We do not have useful' job specific information.

Least squares can be applied directly to bld data to estimate the parameters in equation (2). Ordinary least squares (OLS) applied to competitive bid data will give consistent estimates of the parameters (assuming that sample selection issues can be ignored, say because all eligible bidders submit bids). Residuals can then be constructed from the OLS parameter estimates. The auction-specific varlance is estimated by the auction mean squared residual. A feasible generalized least squares estimate is then obtained by using the auction-specific variances to weight the data.

Firm costs are not observed, so the equilibrium condition of equation ( 1 ) cannot be checked directly. Nevertheless, abnormalities in cartel bidding can be detected using the estimated model. For example, suspicious behavior may be indicated by behavioral differences between cartel and competitive bidders. In particular, tests of differences in the 
coefficients in equation (2), when estimated from cartel and competitive bids, may be informative. of course, differences in bidding behavior across sets of firms may be due to unmeasured auction-specific cost differences, or more general firm characteristics.

\section{Analysis Based on the Ranking of Bids}

Detecting bid-rigging directly from bid data is difficult. As suggested above, abnormalities may be suggested by the bid data, but no strong conclusion can be drawn directly from this evidence. By instead analyzing a firm's expected probability of winning, the construction of tests for phantom bidding are more direct and less qualified. From a practical point of view, firms submitting phantom bids know that a designated firm will submit a bid lower than their own. Complementary bids have no probability of winning, by design. These bids may be intended to create the appearance of competition, or to affect the buyer's expectations of the costs of future jobs (as suggested by Feinstein, Block, and Nold (1985)). The designated low cartel bidder, however, must bid competitively against any firms outside the cartel. The designated low cartel bidder and other competitive bidders must balance the level of a bid with the probability of winning. Fundamental differences may then exist between the ordering of competitive and cartel bids conditional on the observed data; this difference is the focus of our analysis. 
Note that we can remain agnostic about how the low cartel bidder is selected. The designated winner could be chosen on efflclency grounds, according to the distribution of costs, or the choice may satisfy some equity criteria to maintain ring discipline, according to whose "turn" has come. If the cartel low bid originates from the low cost firm, then one might expect the estimated parameters for the low bid probabilities to be similar for the two groups of firms. In any event, our rank-based test is designed to detect differences in the ordering of higher bids, as opposed to the determinants of the probability of being the lowest bid, for each set of firms. Unless the higher cartel bids are competitive, we do not expect their ordering to necessarily reflect observable cost differences.

Using equation (2), the linear approximation to the equilibrium bid function, we can characterize the probability of winning. We approximate the probability of submitting the lowest bid with a multinomial logit (MNL) model, such that,

$$
\ln P\left[b_{1 t}<b_{j t}, \forall j \times i\right]=\theta_{t}+\beta \frac{X_{1 t}}{\sigma_{t}} \sqrt{\frac{\pi}{6}}
$$

where $\theta_{\mathrm{t}}$ is an auction-specific constant, and $\beta$ and $\sigma_{\mathrm{t}}$ are the coefficients from equation (2). The parameters can be estimated (using the procedure described below) from the ranked bid data and equation (3) . 
Equation (3) could be derived directly from equation (2) if (minus one times) the error term in equation (2) is distributed as a Type-1 extreme value random varlable. ${ }^{14}$ In that event, the two approaches are algebraically equivalent.

Parameter estimation proceeds as follows. First, variances are estimated as above, using competitive bid data, and the data are deflated using the estimated auction-specific standard deviations. The deflated data (times minus one) are denoted $Z$. The resulting model gives the log probability of firm $i$ winning auction $t$ as a standard MNL. That is,

$$
\operatorname{In} P\left[b_{i t}<b_{j t}, \forall j \neq i\right]=\alpha_{t}+\beta Z_{1 t}
$$

Exponentiating the log probabilities, and requiring that the individual probabilities sum to one, yields the familiar form

$$
P\left[b_{1 t}<b_{j t}, \forall j \neq i\right]=\frac{e^{\beta z_{1 t}}}{\sum_{j} e^{\beta Z_{j t}}}
$$

Note that the auction-specific constant term cancels. With the MNL specification, the likelihood of observing any particular ranking of bids on a contract can be expressed as the product of individual choice probabilities. ${ }^{15}$ Denoting the index of the firm with

14 See McFadden (1973).

15 See Beggs, Carde11, and Hausman (1981). 
bid ranked $m$ by $r_{m}$, the likelihood of the observed ranking for auction $t$ can be written, if $n_{t}$ bids are submitted,

$$
P\left[b_{r_{1} t}<b_{r_{2} t}<\ldots<b_{r_{n_{t}}} t\right]=\prod_{1=1}^{n_{t}} \frac{e^{\beta 2_{r_{1} t}}}{\sum_{j=1}^{n_{t}} e^{\beta z_{r_{j} t}}}
$$

The likelihood of observing the rankings of the data from all auctions in the sample is then given by

$$
L(\beta)=\prod_{t=1}^{T} \prod_{1=1}^{n_{t}} \frac{e^{\beta Z_{r_{1} t}}}{\sum_{j=1}^{n_{t}} e^{\beta z_{r_{j} t}}}
$$

Since this is the likelihood function for data obtained from a simple choice experiment with varying choice sets, the model can be estimated using standard maximum likelihood routines for the MNL.

When the model is correctly specified, the parameters can be estimated using any subset of the data. In particular, the likelihood function can be factored into two independent parts: the likelihood of observing the low bidders from all auctions and the likelihood of observing all other rankings of bids from those auctions. If the estimates from the two subsets of competitive bids are not statistically different, then model misspecification is not suggested. A likelihood ratio can be formed to test the hypothesis that these coefficients are 
identical. ${ }^{16}$ Under the null hypothesis of no phantom bidding (and given a correctly specified model), parameters estimated using only the lowest cartel ranks and those estimated from higher cartel ranks should be the same. The same likelihood ratio test applied to these data may lead to rejection for two reasons. First, the model may be misspecified for some reason other than the presence of phantom bidding. Of course, the test would lead to rejections if a variable was omitted which affected high bids differently than the low bid. But if the test were applied to competitive data and did not lead to a rejection, then it is less likely that a specification error of this type has been made. Second, the source of the rejection could be an effect which is common to nonwinning cartel bids but not nonwinning competitive bids. Under the assumptions of the model, the rejection is likely to be the result of phantom bidding.

IV. DATA

We analyze a subset of all Nassau and Suffolk County DOT contract lettings from April 1979 through March 1985. Only contracts involving paving are

See Hausman and Ruud (1987). 
considered. ${ }^{17}$ Joint bids are excluded from the analysis. ${ }^{18}$ A total of 575 bids were submitted on 116 projects. Competitive firms submitted 319 bids on the 75 projects where at least two competitive bids were submitted. The jobs receiving one or fewer competitive bids are dropped from the sample, since an auction-specific variance is not identified by the data. The remaining competitive observations are used directly in the estimation. Cartel firms submitted 157 bids in the 75 auctions considered.

The variables are constructed from data for these auctions from the DOT "Notice of Tabulation." Three different data sets are used in the estimation. The first consists of bid data and the exogenous varlables indicated below. These data are used to estimate the parameters using least squares. The second data set, used to estimate the competitive MNL model, consists of the same exogenous variables and the ranking of competitive bids rather than the level of the bid. The third data set consists of the same exogenous variables and the rankings of cartel bids. These data are used to estimate the cartel MNL model.

17 Contracts involving items like mowing, painting and traffic signals are not used in the estimation. Auctions for paving jobs exhibit most strongly the market features that may facilitate collusion.

18 Joint bids represent less than 2 percent of all bids submitted on contracts involving paving. 
The exogenous variables include measures of backlog, capacity, and headquarters location.

Job backlog may contribute to differences in incremental cost across firms. A firm with a large backlog of work may face large incremental costs for an additional job. The variable BACKLOG is defined as the sum of the dollar values of DOT contracts won but not yet completed by a particular firm. The jobs are assumed to be completed in about three months, working at a constant pace.

In order to capture relatively permanent differences between firms, a capacity measure $\mathrm{CAP}_{1}$ for firm $i$ is defined to be the maximum BACKLOG carried by that firm during the sample period. Hence $\mathrm{CAP}_{1}=$ $\max _{t}\left(B A C K L O G_{1 t}\right\}$. In order to account for possible nonlinearities, we include squared capacity, CAPSQ, and a dumny variable that equals one for non-cartel firms that never won an auction, NOBACK. (So NOBACK $=1$ if $\mathrm{CAP}_{1}=0$.)

Firm backlog at a given time is expressed as a utilization rate, UTIL, where $\mathrm{UTIL}_{1 t}=\mathrm{BACKLOG}_{1 t} / \mathrm{CAP}_{1}$. (If $\mathrm{CAP}_{1}=0$, then $\mathrm{UTIL}_{i t}=0$ for all t.) Again, to account for nonlinearities, we include the squared utilization rate, UTILSQ.

Geographic proximity to a job may lead to a cost advantage. For example, the firm with an asphalt batch plant closest to a paving job would have a cost advantage over other bidders. The dummy variable ISLAND $_{i}$ equals one if the headquarters of bidder $i$ is 
on Long Island, and zero otherwise. All cartel firms were headquartered on Long Island.

Apart from the bids themselves, we were unable to obtain any job specific data, such as an engineer's estimate of costs, and so we rely on the auction specific constants to capture any such differences.

The dependent variable in the least squares regressions is $\mathrm{BID}_{1 \mathrm{t}}$, the logarithm of the bid of firm 1 on job $t$, where bids are expressed in hundreds of thousands of constant 1969 dollars. The mean competitive bid was $\$ 450,000$, whlle the mean cartel bid was $\$ 713,000$.

\section{v. RESULTS AND INTERPRETATION}

Analys is of Bid Levels

The results of generalized least squares estimation using bid data for all paving jobs are given in Table 4. (Absolute values of estimated $t$ statistics are reported below the parameter estimates.) We report estimation results using three subsets of data: bids from all firms, bids from competitive firms, and bids from cartel firms only. In all three cases, the same auction-specific variance weights, derived from competitive bids, were employed. In addition, auction-specific constants are estimated, but not reported. If all bids are in fact competitive, all three estimate the same underlying parameters. If cartel bids are not competitive, then the model is misspecified, and only those based on competitive bids are consistent. 
Table 4. GLS Estimates*

\begin{tabular}{|c|c|c|c|}
\hline & $\begin{array}{l}\text { Data From } \\
\text { All Firms }\end{array}$ & $\begin{array}{l}\text { Data From } \\
\text { Competitive } \\
\text { Firms }\end{array}$ & $\begin{array}{l}\text { Data From } \\
\text { Carte1 } \\
\text { Firms }\end{array}$ \\
\hline Observations & 476 & 319 & 157 \\
\hline $\begin{array}{l}\text { Degrees of } \\
\text { Freedom }\end{array}$ & 395 & 238 & 81 \\
\hline Wald Statistic & 21.9 & 494.7 & 28.4 \\
\hline UTIL & $\begin{array}{r}-0.0053 \\
(0.2)\end{array}$ & $\begin{array}{r}-0.0973 \\
(2.8)\end{array}$ & $\begin{array}{c}0.1991 \\
(1.2)\end{array}$ \\
\hline UTILSQ & $\begin{array}{r}0.0358 \\
(1.0)\end{array}$ & $\begin{array}{r}0.1720 \\
(4.0)\end{array}$ & $\begin{array}{r}-0.1143 \\
(0.8)\end{array}$ \\
\hline NOBACK & $\begin{array}{r}-0.0010 \\
(0.1)\end{array}$ & $\begin{array}{r}-0.0178 \\
(1.6)\end{array}$ & \\
\hline CAP & $\begin{array}{r}0.1666 \\
(1.8)\end{array}$ & $\begin{array}{r}-1.2691 \\
(10.4)\end{array}$ & $\begin{array}{r}1.8225 \\
(4.6)\end{array}$ \\
\hline CAPSQ & $\begin{array}{r}-0.4430 \\
(2.1)\end{array}$ & $\begin{array}{l}4.8519 \\
(13.0)\end{array}$ & $\begin{array}{r}-2.9029 \\
(4.4)\end{array}$ \\
\hline ISLAND & $\begin{array}{r}-0.0288 \\
(0.6)\end{array}$ & $\begin{array}{r}-0.0334 \\
(1.2)\end{array}$ & \\
\hline
\end{tabular}

* Absolute values of t-statistics are displayed in parentheses. Auction-specific constants were included, but are not reported to save space. The Wald statistics are for a test of the joint significance of the reported coefficients. The coefficients of CAP and CAPSQ are scaled up by $10^{4}$ and $10^{8}$, respectively.

In general, the competitive model fits well, and the estimates are of the expected sign. Long Island firms bid about 3 percent lower than nonresident firms. Job backlog and capacity affect bids significantly. As UTIL increases, bids decrease over a small range and then increase, other things equal. 
At a utilization rate of 30 per cent, bids are about 1.5 per cent lower than usual. At full capacity, when UTIL is one, bids are about 7.5 per cent higher. Similarly, bids are first a decreasing function of capacity, and then increasing, with only one firm in the sample beyond the minimum point. A Wald test of whether the displayed variables have zero coefficients yields a test statistic of 494.7, which is distributed as a chi-square random variable with 6 degrees of freedom under the null. Thus, the included variables add significantly to the predictive power of the competitive model.

The parameters identified by the cartel data are also reported. Since all cartel firms are from Long Island, the ISLAND parameter is not identified. The signs of the coefficients differ for cartel firms and competitive firms. Many of the cartel estimates do not have the expected sign.

of course, if the cartel model is misspecified, then results using both cartel and competitive data are potentially biased. A Chow test for equality of the coefficients estimated using all the data, versus those obtained from the competitive and cartel data separately, can be constructed. Under the null hypothesis of no bid-rigging, the estimates obtained from the two subsamples are identical to those from the full sample. The test statistic, which is distributed as an $F$ random variable with $(76,319)$ 
degrees of freedom under the null, equals 9.38. We can reject the null hypothesis of no bid-rigging.

Based on these results, we are lead to two conclusions. First, the model fits the competitive data reasonably well. Second, bids from cartel firms statistically differ from those of competitive firms. The following results suggest the reasons for the differences between the two types of bids.

\section{Analysis of Competitive Bid Rank Data}

The estimates from the MNL model using competitive data are similar to the results in Table 4. The competitive MNL estimates are presented in Table 5. (Estimated $t$ statistics are included below the parameter estimates.) Estimates are given using three different data sets: all ranks, lowest ranks and higher ranks. The estimates are stable over ranks. The likelihood ratio test statistic of coefficient stability across ranks is 4.3 , which is distributed as a chi-square random variable with six degrees of freedom under the null hypothesis. The test statistic is significant at about the 36 percent level, and therefore, we cannot reject the null hypothesis of no model misspecification. We cannot conclude that competitive bids are generated by a different process depending on whether they are low or not. 
Table 5. Competitive Rank Based Estimates*

\begin{tabular}{|c|c|c|c|}
\hline $\begin{array}{l}\text { Observations } \\
\text { Log Likelihood }\end{array}$ & $\begin{array}{l}\text { A11 Ranks } \\
244 \\
-291.4\end{array}$ & $\begin{array}{c}\text { Low Ranks } \\
75 \\
-89.85\end{array}$ & $\begin{array}{c}\text { Higher } \\
\text { Ranks } \\
169 \\
-199.4\end{array}$ \\
\hline UTIL & $\begin{array}{r}-0.0070 \\
(0.1)\end{array}$ & $\begin{array}{r}0.0161 \\
(0.1)\end{array}$ & $\begin{array}{r}-0.0522 \\
(0.3)\end{array}$ \\
\hline UTILSQ & $\begin{array}{r}0.0986 \\
(0.8)\end{array}$ & $\begin{array}{r}0.0534 \\
(0.3)\end{array}$ & $\begin{array}{r}0.1596 \\
(1.0)\end{array}$ \\
\hline NOBACK & $\begin{array}{r}-0.0283 \\
(1.0)\end{array}$ & $\begin{array}{r}0.0089 \\
(0.2)\end{array}$ & $\begin{array}{r}-0.0454 \\
(1.3)\end{array}$ \\
\hline CAP & $\begin{array}{r}-1.888 \\
(3.8)\end{array}$ & $\begin{array}{r}-1.641 \\
(2.4)\end{array}$ & $\begin{array}{r}-2.100 \\
(3.0)\end{array}$ \\
\hline CAPSQ & $\begin{array}{c}6.869 \\
(3.9)\end{array}$ & $\begin{array}{r}6.517 \\
(2.6)\end{array}$ & $\begin{array}{c}7.020 \\
(2.9)\end{array}$ \\
\hline ISLAND & $\begin{array}{r}-0.0182 \\
(0.3)\end{array}$ & $\begin{array}{r}-0.0759 \\
(0.9)\end{array}$ & $\begin{array}{r}0.1016 \\
(0.9)\end{array}$ \\
\hline
\end{tabular}

* Absolute values of t-statistics are displayed in parentheses. The coefficients of CAP and CAPSQ are scaled up by $10^{4}$ and $10^{8}$, respectively.

Analysis of Cartel Bid Rank Data

Estimates from the MNL model using cartel data are presented in Table 6 . The estimated coefficients are similar to the GLS estimates for the cartel data presented in Table 4, and differ from all the competitive estimates. The likelihood ratio test statistic of parameter stability across ranks is 8.94 . which is distributed as a chi-squared random variable with four degrees of freedom under the null hypothesis. The test statistic is significant at about the 94 percent level. Therefore, we reject the 
Table 6. Cartel Rank Based Estimates

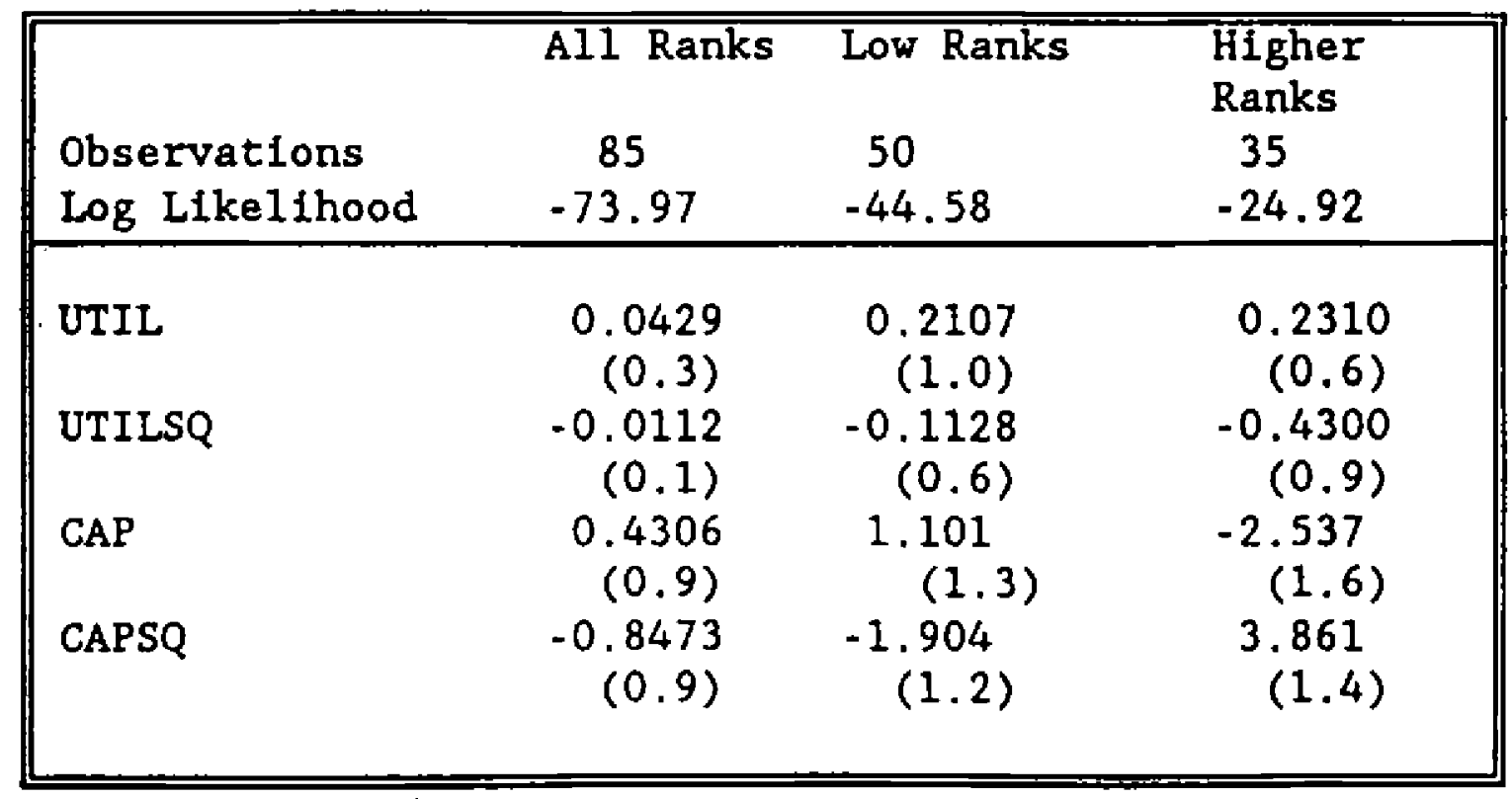

* Absolute values of t-statistics are displayed In parentheses. The coefficients of CAP and CAPSQ are scaled up by $10^{4}$ and $10^{8}$, respectively.

null hypothesis of no phantom bidding. We conclude that cartel bids are generated by a different process depending on whether they are low or not.

VI. CONCLUSIONS

The idiosyncracies of the DOT auction market suggest both a candidate cartel and a particular bidrigging mechanism. We find that the ranking of cartel bids does not coincide with rankings of costs. We reject the null hypothesis of no phantom bidding in cartel data. The bid ranking may not colncide with cost rankings because of the presence of phantom bids. In the competitive data, bids increase with costs as expected, and we cannot reject the hypothesis of no 
phantom bidding for competitive firms. Because we have no reason to believe that the difference between cartel and competitive bidding is structural, we may have found evidence of cartel activity.

Our testing procedure may be conservative in that we may have inadvertently classified some cartel participants as competitive. Simllarly, we have access to a relatively sparse set of explanatory variables. Therefore, it is perhaps best to view the contribution of this paper as methodological, as well as descriptive. Unfortunately, if an antitrust authority or procurement agency were to publicly announce the adoption our test procedure, it would be relatively easy for an effective cartel to tailor its phantom bids to disguise collusive behavior. For example, all cartel firms could scale their competitive bids up by the same percentage. The bid ranking would then coincide with cost rankings. If the cartel was not inclusive, differences between cartel and competitive bidding would be consistent with cost asymmetries between the two groups of firms. Presumably, a non-inclustve cartel is profitable when cartel firms enjoy a cost advantage over competitive flrms. Absent prior information on cost differences, bidding differences could not be attributed solely to non-competitive bidding. Attention would then have to focus on the determination of the identity of the lowest bidder, or on rates of return. 


\section{References}

Beggs, S., Cardell, S., and Hausman, Jerry A. "Assessing the Potential Demand for Electric Cars." Journal of Econometrics 17 (1981): 1-20.

Comanor, W.S. and Schankerman, Mark A. "Identica1 BIds and Cartel Behavior." Bell Journal of Economics 7 (Spring 1976): 281-286.

Feinstein, Jonathan S., Block, Michael K., and Nold, Frederick C. "Asymmetric Information and Collusive Behavior in Auction Markets." American Economic Review 75 (June 1985): 441460 .

Hausman, Jerry A., and Ruud, Paul A. "Specifying and Testing Econometric Models for Rank-Ordered Data." Journal of Econometrics 34 (1987): 83104.

Hendricks, Kenneth, and Porter, Robert H. "Collusion in Auctions." Annales d'Economie et de Statistique 15/16 (July-December 1989): 217-230.

Howard, Jeffrey H., and Kaserman, David. "Proof of Damages in Construction Industry Bid-Rigging Cases." The Antitrust Bulletin (Summer 1989): 359-393.

Joyner, Alphonso D. "Bid Rigging by Highway Contractors and the Resulting Dispute Over Recorded Overcharges: The United States v. the States." American Business Law Journal 23 (1985): 417-450.

Lang, K. and Rosenthal, R. "The Contractors' Game." RAND Journal of Economics 22 (Autumn 1991): 329 338 .

McClave, J., Rothrock, T., and Ailstock, J.P. "Computerized Economic and Statistical 
Investigation of the Florida School Bread Market." Southeastern Anti-Trust Review 1 (1978): $13-54$.

McFadden, Daniel. "Conditional Logit Analysis of Qualitative Choice Behavior." In Frontiers of Econometrics, edited by P. Zarembka. New York: Academic Press, 1973.

McMillan, John. "Dango: Japan's Price Fixing Conspiracies." Economics and Politics 3 (November 1991): 201-218.

Newsday. Sunday, November 18, 1984, 3, 30.

U.S. General Accounting office. 1990. General Accounting office Report to House Judiciary Committee Chairman on Changes in Antitrust Enforcement Policies and Activities of the Justice Department, released December 7; reprint, Bureau of National Affairs, Inc. Antitrust and Trade Regulation Report, Special Supplement Vol. 59 No. 1495, December 13.

Zona, J. Douglas. "Bid-rigging and the Competitive Bidding Process: Theory and Evidence." Ph.D. dissertation, State University of New York at Stony Brook, 1986. 